\title{
Birder Specialization Differences in Conservation Involvement, Demographics, and Motivations
}

\section{GLEN T. HVENEGAARD}

\author{
Department of Geography \\ Augustana University College \\ Camrose, Alberta, Canada
}

\begin{abstract}
Birders represent a significant component of wildlife users, but birders are not a homogeneous group. This study develops a recreation specialization framework for birders in a non-North American setting, and examines how conservation involvement, demographics, and motivations vary among specialization levels. Using questionnaire data from birders in Doi Inthanon National Park, Thailand, three specialization levels-novice, advanced-active, and advanced-experienced-are described. Specialization level was positively, but weakly, related to conservation involvement. Age, income, and percentage male rose with specialization level. Both advanced birder types were less interested in nonbirding activities than novice birders. Advanced-experienced birders were most interested in birding activities. Management and marketing implications are discussed.
\end{abstract}

Keywords birders, specialization, conservation involvement, demographics, motivations, Thailand

\section{Introduction}

Wildlife watchers represent a significant component of all wildlife users (Federal-Provincial-Territorial Task Force, 1999), based on number of participants, level of participation, and expenditures. For similar reasons, birders are an important segment of wildlife watchers (Jacquemot \& Filion, 1987). For effective management, it is useful to understand the potential benefits and unique characteristics of this user group. This paper examines three of these-conservation involvement, demographics, and motivations.

First, conservation involvement is examined because, as a subset of ecotourism, birding should be expected to contribute to ecotourism's goal of en-

Financial support for this research was provided by the International Development Research Center, and the Canada-ASEAN Center/Asia Pacific Foundation. The staff of DINP and research assistants were very helpful. Thanks also to Bonnie McFarlane and two anonymous reviewers for their useful comments.

Address correspondence to Glen T. Hvenegaard, Department of Geography, Augustana University College, 4901-46 Avenue, Camrose, Alberta T4V 2R3, Canada. E-mail: hveng@augustana.c a 
hanced conservation (Hvenegaard \& Dearden, 1998). Most research has described conservation contributions for a particular birding group or compared a birding group with other recreation groups or the general public (e.g., Butler \& Fenton, 1987; Witter \& Shaw, 1979). However, except for McFarlane \& Boxall (1996), little research has assessed how support for, and involvement in, conservation varies within a birding group.

Second, an understanding of demographics is important to effectively manage environmental impacts (Butler \& Fenton, 1987), improve economic benefits (Hvenegaard, Butler, \& Krystofiak, 1989), optimize educational programs (Beck \& Cable, 1998), or advertize to potential markets (Hvenegaard \& Dearden, 1998). Birders tend to be slightly older, more educated, more employed in professional occupations, and have higher incomes than the general public (Hvenegaard et al., 1989; Hvenegaard \& Dearden, 1998; Kellert, 1985). However, only a few studies have shown how these characteristics vary within a birding group.

Third, information about motivations is important to assist in predicting the type and level of demand for recreation sites and assessing satisfactions (Manning, 1986). As expected, birders are motivated by seeing birds, but also want to be outdoors, gain birding skills, compete with others, contribute to conservation, be with family and friends, and meet others (Boxall, Stelfox, \& Hvenegaard, 1991; Hvenegaard \& Manaloor, 2001; McFarlane, 1994). Again, only a few studies have tested for differences in motivations within a birding group.

Like many other recreation user groups, birders are not a homogeneous group. Several researchers have conceptualized, and tested for, potential birder subgroups, and a number of typologies have been proposed for birders, all of which have been based on North American data. For example, Butler and Fenton (1987) used motivations and activities as a classification scheme. Boxall and McFarlane (1993) asked birders to rank themselves as either casual, novice, intermediate, or advanced, based on level of activity and intensity of interest. Birders can also be grouped according to wildlife knowledge, bird identification skill, participation in birding activities, membership in birding organizations, and use of birding equipment (Applegate, Otto, \& Buttitta, 1982; Cole \& Scott, 1999; Kellert 1985). The most promising method of identifying birder subgroups uses the recreation specialization model (McFarlane, 1994).

\section{Recreation Specialization}

Recreation specialization "refers to a continuum of behaviour from the general to the particular, reflected by equipment and skills used in the sport and activity setting preferences" (Bryan, 1977, p. 175). Over time, participants would move along a continuum from low involvement and general recreational interests to high involvement and more specific interests (Bryan, 2000). For example, novice birders would participate infrequently with a variety of motivations, whereas advanced birders would participate more frequently with more specific motivations. 
Recreation specialization can be used to increase an understanding of user groups and desired resource and desired activity characteristics. Site managers can use specialization information to manage resources and can even influence the specialization process to achieve desired management goals.

Specialization frameworks have been proposed for a variety of outdoor recreation groups, including birders (McFarlane, 1994), anglers (Chipman \& Helfrich, 1988), hunters (Kuentzel \& Heberlein, 1992), canoeists (Kuentzel \& McDonald, 1992), and hikers (Virden \& Schreyer, 1988). Although studies describe the components (and the variables used to define them) differently, the differentiating components most commonly used are past experience, economic commitment, and centrality to lifestyle. Past experience, a behavioral component to indicate the amount and type of activities in which an individual has participated (Schreyer, Lime, \& Williams, 1984), can include, for example, years of experience and distance travelled. Economic commitment, another behavioral component, describes, in a monetary sense, the investment of time and effort in an activity (Kuentzel \& McDonald, 1992), and often includes the number and value of equipment items. Centrality to lifestyle, both a behavioral and psychological component, attempts to describe how central an activity is in a person's life to the exclusion of other activities (Ditton, Loomis, \& Choi, 1992). Variables often used include the rate of participation, memberships in related groups, and attitudes about the activity.

Additional conceptual development of the specialization concept is found in Bryan (1977) and Ditton et al. (1992); only those aspects directly related to conservation, demographics, and motivations are described here. First, related to conservation, Ditton et al. (1992) proposed that as specialization increases, dependency on a specific resource will increase. In other words, preferences for certain resource characteristics will emerge over time. Therefore, to obtain and maintain these resource characteristics for outdoor recreation users, it is assumed that more specialized users will be more involved in conservation and less involved in consumption than less specialized users (Bryan, 1977). Resource dependency has been supported by research on anglers (Chipman \& Helfrich, 1988; Ditton et al., 1992) and backcountry hikers (Virden \& Schreyer, 1988). For canoeists, only weak support was found (Wellman, Roggenbuck, \& Smith, 1982).

For birders, specialization is positively correlated with conservation, as measured by memberships in wildlife-related organizations (Boxall \& McFarlane, 1993). Similarly, specialization level is positively correlated with conservation contributions (McFarlane \& Boxall, 1996). However, the proportion rating conservation as their primary motivation for birding was higher for intermediate and novice birders than advanced birders (McFarlane, 1994). Even so, conservation was the dominant motivation among all birders.

Second, probing deeper into the interests of recreationists, Ditton et al. (1992) proposed that as specialization level increases, the importance of activity-specific elements of the experience will decrease relative to nonactivity-specific elements of the experience. That is, specialized users will gain a more holistic view of their 
experience. This notion was further conceptualized by Duffus and Dearden (1990) and supported by research on anglers (Ditton et al., 1992), hikers (Virden \& Schreyer, 1988), and goose hunters (Kuentzel \& Heberlein, 1992). Similarly, for birders (Cole \& Scott, 1999) and wildlife viewers (Martin, 1997), more specialized users had greater interest in all species of wildlife than novices. Kellert (1985) found that committed birders (able to identify $\geq 40$ species) were motivated primarily by a personal fascination with birds and casual birders (able to identify $\leq 10$ species) were motivated primarily by the aesthetic qualities of birds. However, contrary to Ditton et al. (1992), McFarlane (1994) found that the desire for achievement increases with higher levels of birder specialization, motivations about the whole experience decrease with higher levels of specialization, and conservation motivations were highest with intermediate levels of specialization.

In addition to the conservation and motivations, specialization can also be applied to demographics. Birders tend to have a higher age, education, income, professional employment, and percent male than nonbirders (Butler \& Fenton, 1987; Hvenegaard \& Dearden, 1998; Kellert, 1985). Knowing that there is a specialization progression between groups, one might expect a similar demographic progression among specialization levels (Kerstetter, Confer, \& Graefe, 2001), but only a few studies have conducted such tests on birders. Kellert (1985) found that committed birders were more likely to be male than casual birders. Boxall et al. (1991) found that specialization level, measured by self-reported skill level, was positively correlated with percentage male, with probable positive correlations to age and education. McFarlane (1994) also found a positive correlation for percent male, but no correlations for age, education, income, or place of residence. Martin (1997) found positive correlations for education and income, but a negative correlation for age. Finally, Cole \& Scott (1999) found positive correlations for percentage male, age, income, and education.

The purpose of this study is to develop, in an ecotourism setting, a birder specialization framework, using variables representative of past experience, economic commitment, and centrality to lifestyle. A case study in northern Thailand will be used to test the level of specialization against conservation involvement, demographics, and motivations. Specific hypotheses are: 1) more specialized birders will be more interested and involved in conservation than less specialized birders; 2) more specialized birders will have a higher age, education, rate of professional employment, and percent male than less specialized birders; and 3) as specialization level increases, the importance of activity-specific motivations will decrease relative to nonactivity-specific motivations.

\section{Methods}

\section{Study Site}

Foreign and domestic bird watchers are attracted by the high bird diversity in Thailand (with over 916 species recorded). Northern Thailand is especially popu- 
lar because of numerous protected areas, easy access, and a relatively high level of conservation (Round, 1991). The government of Thailand is hoping that increased ecotourism will promote local economic development and increased conservation (Tourism Authority of Thailand, 1995).

Doi Inthanon National Park (DINP) is located in northern Thailand, about $80 \mathrm{~km}$ southwest of Chiang Mai. The mountainous park includes the highest peak in Thailand. Within its 48,240 hectares, the park contains a variety of natural and disturbed habitats. The park has recorded 382 bird species, the highest for any site in Thailand (Round, 1989). Facilities for park visitors include a paved road to the summit, campground, bungalows, restaurants, and visitor centers. Other attractions for visitors include waterfalls, walking trails, scenic overlooks, religiously significant sites, caves, relatively cool climate, and the hilltribe people.

Over 900,000 park visits were recorded in 1993, triple that of 1983 (Hvenegaard \& Dearden, 1998). Due to the high number of bird species and easy access, the park is very popular for bird watching (Round, 1991), although birders are greatly outnumbered by visitors engaged in other activities. Peak birding months are from December to March, corresponding to the breeding period for resident birds and wintering period for visiting birds.

\section{Sampling and Analysis}

From November, 1993 to March, 1994 we interviewed birders at DINP. Birders were defined as those visitors who visibly participated in birding activities (based on clues such as visiting popular birding sites and using binoculars, spotting scopes, and bird books). Using a common questionnaire, birders were interviewed in a personal or self-administered fashion. Only respondents aged 16 or more were interviewed. Most respondents were interviewed at the two sites visited most often by birders, the Doi Inthanon Bird Center and summit area. A small number of respondents were interviewed at the campground and on trails. Self-administered questionnaires were distributed by the owner of the Doi Inthanon Bird Center.

The three components commonly used in specialization studies (past experience, economic commitment, and centrality to lifestyle) were represented by five behavioral variables (number of birding equipment items, cost of those items, number of years birding, number of birding days last year, and proportion of birding days to travel days). Variables were standardized to a mean of 0 and a standard deviation of 1 . Principal component analysis, with varimax rotation, was used to identify specialization components. Components with an eigenvalue of 1 or more were extracted. A minimum factor loading of 0.30 was used to identify variables belonging to a component. Cronbach's alpha was used to examine scale reliability. Factor scores were then used in a K-Means cluster analysis to determine specialization clusters, based on nearest centroid sorting. Data from the first few cases were used as initial, temporary cluster centers, and then updated in an iterative process to minimize Euclidean distance from each case to the cluster 
center. The maximum number of iterations for updating of cluster centers was 10 , but terminated if the largest change in any cluster center was less than $2 \%$ of the minimum distance between initial centers. Clustering stopped before the last new cluster resulted in a cluster size less than $5 \%$ of total sample.

Occupations were collapsed into six categories. The data were analyzed with SPSS. Chi-square tests and one-way analyses of variance were used to test hypotheses. Post-hoc multiple comparisons used Tukey's Honestly Significant Difference test.

\section{Results}

Using extrapolations of birder counts at the Doi Inthanon Bird Centre, we estimated 370 birders visited DINP during the study period. Of these, we interviewed 137,33 personally (100\% response rate) and 104 with a self-response questionnaire $(98 \%$ response rate).

\section{Recreation Specialization}

Because of missing values, only 97 responses could be used in the specialization analysis. A principal components analysis was used on five variables intended to identify birder specialization levels. The Kaiser-Meyer-Olkin measure of sampling adequacy of 0.65783 is classified as mediocre (Norusis, 1993). Using Bartlett's test of sphericity, the correlation matrix was not an identity matrix.

Only two components were identified for the specialization model (Table 1) because, with three components extracted, the eigenvalue of the last component fell below 1 . Using the varimax rotation method, the solution converged in three iterations. Factor loadings of these principal components were similar to another specialization model for birders (McFarlane, 1994), albeit with one less compo-

TABLE 1 Principal Components of Variables for Birder Specialization Model

\begin{tabular}{lcc}
\hline & \multicolumn{2}{c}{ Principal components } \\
\cline { 2 - 3 } Specialization variables & $\begin{array}{c}\text { Economic } \\
\text { commitment }\end{array}$ & $\begin{array}{c}\text { Centrality } \\
\text { to lifestyle }\end{array}$ \\
\hline Cost of equipment items & $\underline{.83}$ & -.06 \\
Number of equipment items & $\underline{.79}$ & .26 \\
Number of years birding & $\underline{.57}$ & .16 \\
Number of birding days last year & -.02 & $\underline{.90}$ \\
Proportion of birding days to travel days & .43 & $\underline{.65}$ \\
Eigenvalue & 2.15 & 1.02 \\
Variance Explained (total = 63.43\%) & 42.98 & 20.45 \\
Reliability (Cronbach's alpha; total =.65) & 0.64 & 0.46 \\
\hline
\end{tabular}


nent. The economic commitment component consisted of the number of equipment items, their cost, and years of birding. The centrality to lifestyle component consisted of the number of birding days last year and the proportion of birding days to travel days last year. Reliability for this model was .65, using Cronbach's alpha, which was less than McFarlane's model (1994), but similar to Kuentzel \& McDonald's model (1992).

Cluster analysis of these two components produced three groups of birders (Table 2). More specialized birders were divided into two subgroups. Advancedactive birders (10.2\% of the sample) spent more days birding than advancedexperienced birders (Table 3), and thus had a higher score on the centrality to lifestyle component. However, advanced-experienced birders (49.5\% of the sample) had more experience and invested more in birding than advanced-active birders, and thus had a higher score on the economic commitment component. By achieving the highest scores on one of the components, each of these groups warrants an "advanced" designation. Novice birders (40.2\% of the sample) scored lowest on both components.

In terms of trip characteristics, birders stayed an average of 3.2 days in the park, and $39 \%$ of birders had visited the park before. About $23 \%$ of birders travelled to the park as part of a tour group. Birders spent about \$27 (all dollars reported in USD) in the park per day. These were not different among birder specialization levels.

\section{Conservation Interest and Involvement}

For all birders, $84.9 \%$ were willing to donate to conservation at DINP, at an average rate of \$26.94 per person (based on a direct question; Table 4). Two-thirds of birders were members of conservation or wildlife groups (average of 3.8 groups), and over $60 \%$ had donated to wildlife causes in the past year (average of \$129.69 per birder). However, very few foreigners actually made a donation to a Thai conservation cause.

TABLE 2 Specialization Component Scores for Birder Specialization Levels

\begin{tabular}{lccccccc}
\hline & \multicolumn{3}{c}{ Birder specialization level } & & \multicolumn{2}{c}{ Statistics $^{\mathrm{a}}$} \\
\cline { 2 - 5 } Specialization component & $\begin{array}{c}\text { Advanced- } \\
\text { experienced }\end{array}$ & $\begin{array}{c}\text { Advanced- } \\
\text { active }\end{array}$ & Novice & & $F$ & $p$ \\
\hline Economic commitment $^{\mathrm{b}}$ & $1.65^{\mathrm{c}}$ & $-1.32^{\mathrm{d}}$ & $-1.88^{\mathrm{d}}$ & & 78.0 & $<.0001$ \\
Centrality to lifestyle $^{\mathrm{b}}$ & $0.54^{\mathrm{c}}$ & $1.97^{\mathrm{d}}$ & $-1.21^{\mathrm{e}}$ & & 48.3 & $<.0001$ \\
\hline
\end{tabular}

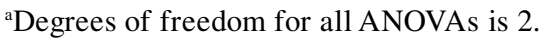

${ }^{\mathrm{b}}$ Any two means that do not have the same superscript are significantly different at $p<0.5$. 


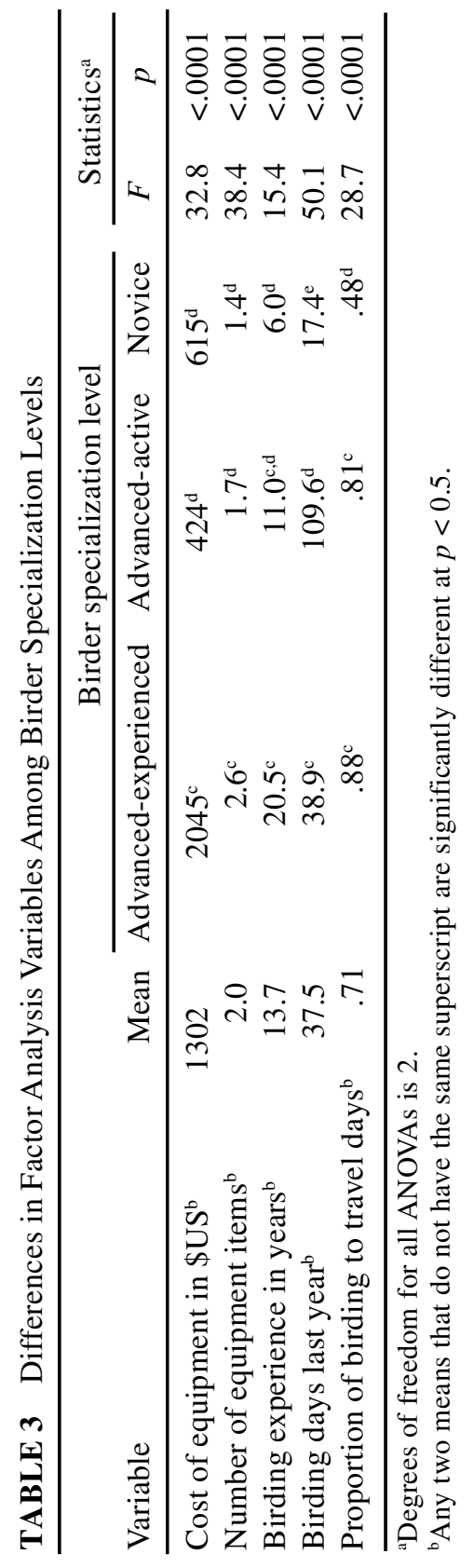


The hypothesis that more specialized birders are more interested and involved in conservation than less specialized birders was partially supported. No differences were found among specialization levels for willingness to donate to DINP conservation (and amount) and actual donation to conservation causes in the past year (and amount; Table 4). Advanced-experienced birders were more likely to be a member of a conservation of wildlife group than other specialization levels. As a result, advanced-experienced birders were members of more groups and had higher annual fees than other specialization levels. Donations to conservation causes in the past year did not vary among specialization levels. The percentage of each group donating to a Thai conservation or wildlife cause was too low to examine potential differences.

\section{Demographics}

The hypothesis about demographic trends among specialization levels of birders was supported for age, income, and gender, but not for education and occupation. Advanced-experienced birders were much older (44.1 years) than both advanced-active (34.1 years) and novice birders $(33.8$ years; $\mathrm{F}=6.5, \mathrm{df}=2, p=$ .0023). Education was not related to birder specialization level, but was extremely high (75\% of all birders had a bachelor's degree or higher). Advanced-experienced birders had the highest average annual personal income $(\$ 36,906)$, followed by advanced-active $(\$ 18,190)$ and novice birders $(\$ 14,250 ; \mathrm{F}=8.1$, df $=2$, $p=.0006)$. Specialization level was not correlated with occupational category. However, the percentage of retirees $(20 \%)$ among advanced-experienced birders was twice that of other birder subtypes. As well, $32.4 \%$ of novice birders were students, compared to only $5.0 \%$ for advanced-experienced and $11.1 \%$ for advanced-active birders. Advanced-experienced and advanced-active birders were more likely to be male ( $82.2 \%$ and $80 \%$, respectively) than novice birders $(37.8 \%$ male; $\mathrm{X}^{2}=18.6$, df $\left.=2, p=.0001\right)$. By country, $30 \%$ of the sample was from Thailand, and $70 \%$ from foreign countries (mostly Europe and North America). The ratios were 23:77 for advanced-experienced birders, 10:90 for advanced-active birders, and 44:56 for novice birders $\left(\mathrm{X}^{2}=6.5\right.$, $\left.\mathrm{df}=2, p=.0389\right)$.

\section{Motivations}

For the entire group, the most important motivations were related to birds (Table 5 ), but other natural history attractions were also important to the birding experience. Social and cultural motivations were much less important. About half of the motivations were significantly different among specialization levels. The hypothesis about motivation differences among specialization levels was not supported. The importance of bird-related motivations (i.e., seeing birds, seeing as many birds as possible, and seeing bird species not seen before) was generally higher for advanced-experienced birders than for novice or advanced-active birders. The 


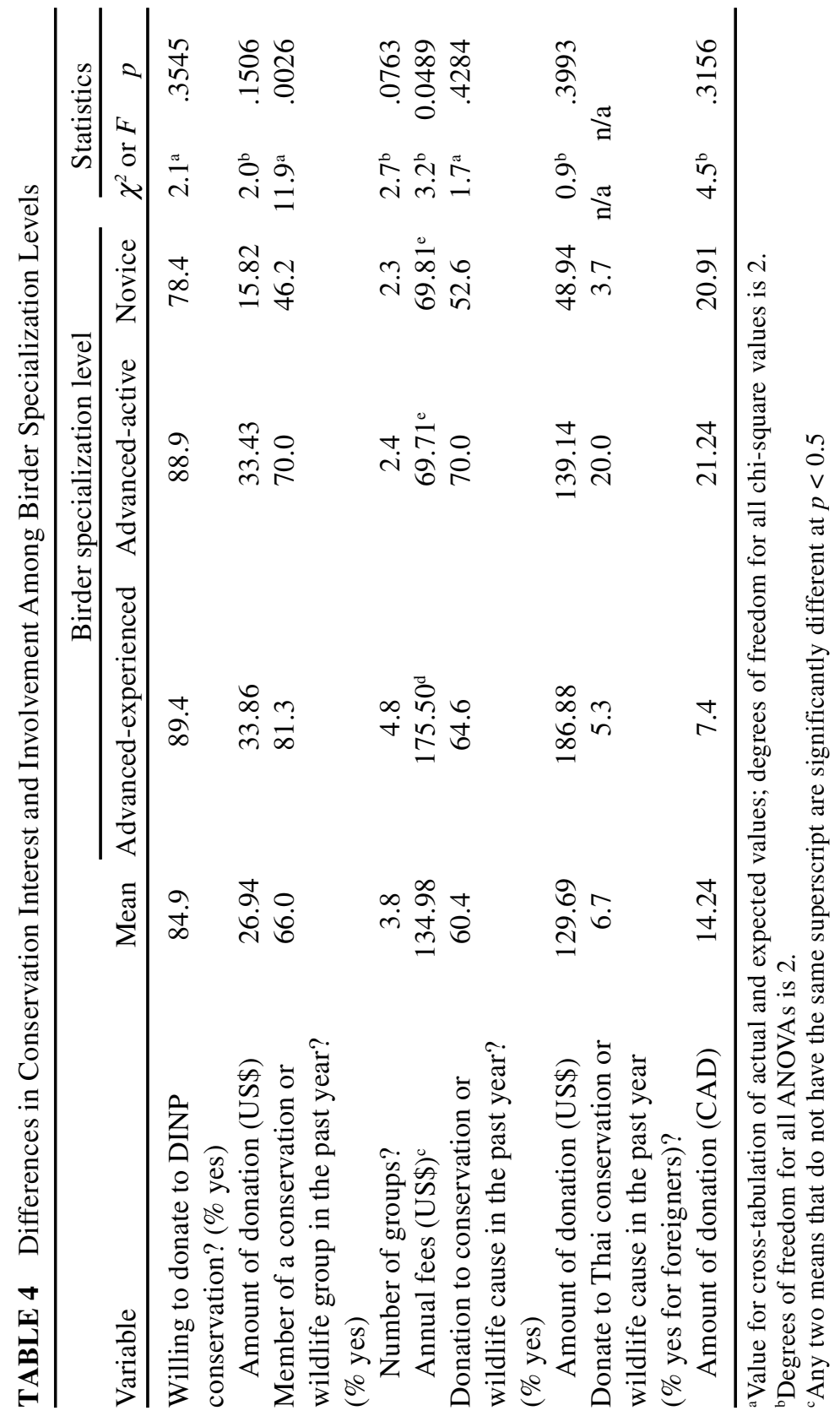




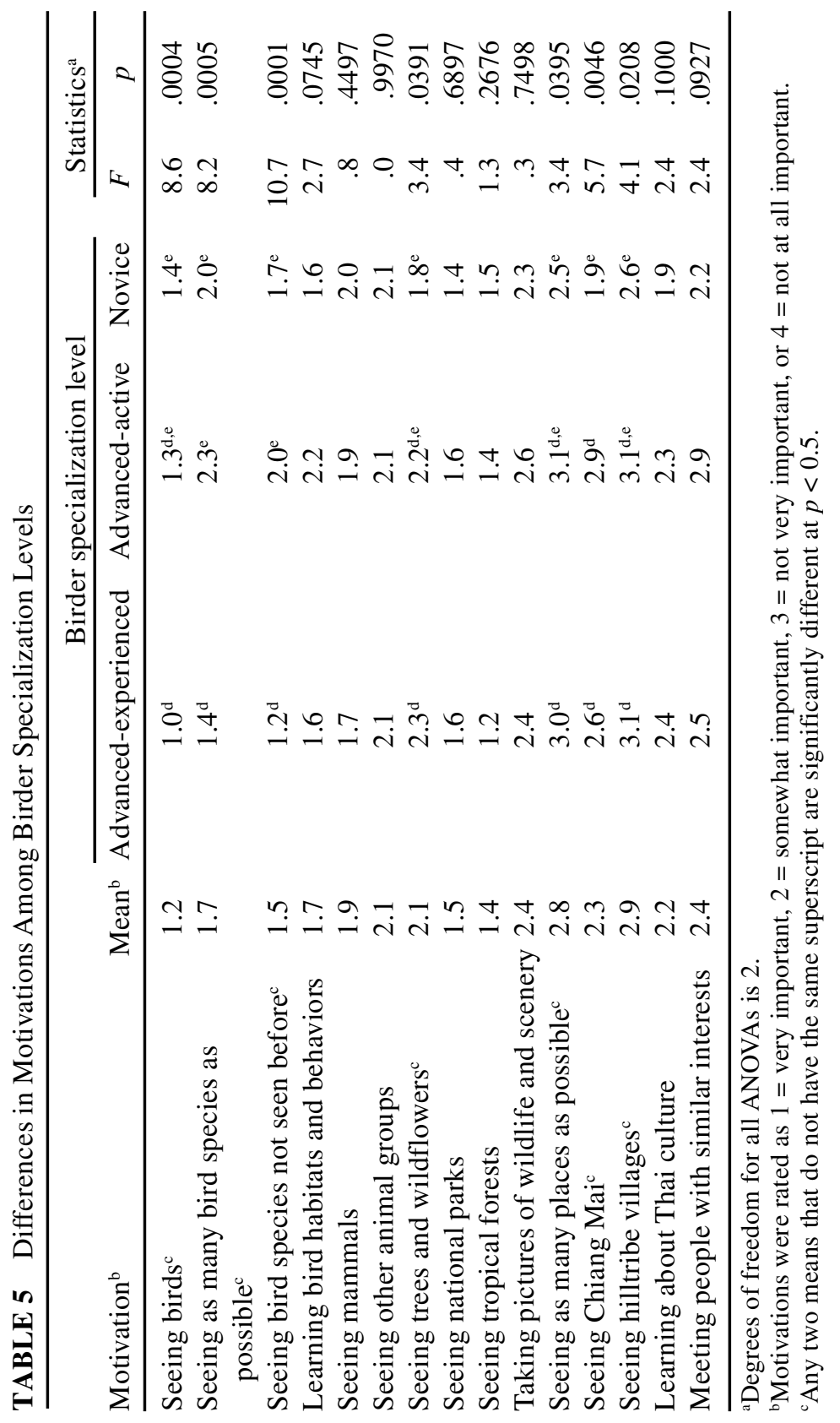


importance of motivations unrelated to birds (i.e., seeing as many places as possible, Chiang Mai, hilltribe villages, and trees and wildflowers) was higher for novice birders than for the two advanced subtypes.

\section{Discussion}

This model of birder specialization is similar to models used in others studies of birders and outdoor recreation user groups. This model's five behavioral variables, representing two principal components, were fewer than most other models, but described three different specialization levels. Unlike other studies, two advanced groups were identified because they each scored high on of the specialization components. By spending the most on birding equipment items, advancedexperienced birders scored highest on the economic commitment component; this is probably influenced by their older age (by about 10 years) and resulting income and time to accumulate equipment. By spending the highest number of days birding last year, advanced-active birders scored highest on the centrality to lifestyle component. This category acknowledges participants who have moderate amounts of experience, but devote over 100 days per year to their sport.

Among all birders, the level of involvement in conservation organizations was similar to other studies of birders (Butler \& Fenton, 1987; McFarlane \& Boxall, 1996; Witter \& Shaw, 1979). Bryan (1977) suggested that, as recreationists become more specialized, they would shift their focus from consumption to conservation. This has been moderately supported in the literature (Boxall \& McFarlane, 1993; McFarlane, 1994; Wellman et al., 1982), and this study also provides limited support. Specialization level was positively correlated with conservation group memberships, but not correlated with actual or hypothetical donations to conservation. Even then, for foreigners, the memberships support conservation in their home countries. For ecotourism sites to be successful, ecotourists should support local conservation initiatives (Hvenegaard, 1994). Though few donations are made to Thai conservation causes, there is a high willingness to do so (85\%). Therefore, to help birding achieve ecotourism's conservation goals, site managers should make visitors aware of the conservation issues, examine possible projects toward which visitors could contribute, and implement appropriate mechanisms to capture the willingness-to-donate (Bramwell \& Fearn, 1996; Hvenegaard \& Dearden, 1998).

Among demographic variables, age, income, and percentage male were positively correlated with specialization level, but education and occupational level were unrelated to specialization. The trends in this study and others mentioned earlier are not consistent, although it appears that birder specialization level is usually positively correlated with age, percentage male, income, and education (Boxall et al., 1991; Cole \& Scott, 1999; Kellert, 1985; Martin, 1997; McFarlane, 1994). These trends have implications for birding tour operators, site managers, 
and watchable wildlife agencies as they seek to market for and manage different birding subgroups (Manning, 1986).

Ditton et al. (1992) proposed that, as specialization level increases, the importance of activity-specific motivations will decrease and the importance of nonactivity-specific motivations will increase. This has been supported for anglers (Ditton et al., 1992), wildlife viewers (Cole \& Scott, 1999), and some birder groups (Martin, 1997), but not for other birder groups (McFarlane, 1994). This study does not support the proposal by Ditton et al. (1992). Compared to novice birders, advanced-experienced birders rated the importance of bird-related motivations higher, and the importance of motivations unrelated to birds lower.

Thus, although this may be one recreational activity in which the activityspecific aspects of the sport increase in importance with specialization, this study has a high proportion of advanced birders (see later). Many of these advanced birders come from other countries to Thailand just to watch birds, and as a result they are very focussed on birds. Some of these advanced birders take part in birding tours that concentrate on bird listing and observing rare birds. Such results are relevant for marketing efforts of birding tour operators, as they try to match birders (and their varied motivations) with appropriate trip activities.

DINP attracts a high proportion of advanced birders. The total percentage in the two advanced categories (59.7\%) is much greater than found for similar categories of Alberta birders (7\%; McFarlane, 1994), Alberta Christmas Bird Counters (11.0\%; Boxall et al., 1991), Montana wildlife viewers (1\%; Martin, 1997), American birders (3\%; Kellert 1985), or New Jersey birders (13\%; Applegate et al., 1982). A few reasons are possible for this trend. First, advanced birders, with their achievement-oriented motivations (McFarlane, 1994), are willing to travel relatively long distances to DINP (i.e., mostly overseas to Thailand). Second, with their relatively high incomes, advanced birders are able to pay the large travel costs. Finally, advanced birders are more likely to know about DINP's birding potential than novice birders.

There are several limitations to this study. Generalizations should be made cautiously because of the uniqueness of DINP and the high proportion of advanced birders. The specialization model could achieve a higher reliability by including additional variables, such as perceived skill level, identification ability, use of a birding life list, ownership and cost of other birding equipment, and membership in birding organizations (e.g., McFarlane, 1994). However, such long questionnaires can be problematic; one study used 17 variables for a birder specialization model (Kim, Scott, \& Crompton, 1997). As well, rather than using membership in conservation groups as an indicator of conservation activity (the dependent variable), this variable could be used determine the specialization level (independent variable).

Previous research has shown that many characteristics of birders are distinct from those of other wildlife user groups. Moreover, this study and others also 
show that specialization subtypes of birders exist and have distinct characteristics. McFarlane (1994) suggests that specialization models, developed with only a few variables, such as self-reported skill levels and identification abilities, may provide a relatively easy means to differentiate birders. Since many independent variables are related, further research is needed to determine which variables are the most useful discriminators of specialization level. For example, when not used to develop a specialization model, years of experience is positively correlated with specialization level (Boxall et al., 1991). Birding experience is also an indicator of equipment expenditures (number of items) since more experienced birders would have more time to purchase equipment items and to increase income level to afford those items. Similarly, more research is needed on the underlying influence of income on other independent variables in the specialization model, such as the cost of equipment items, and rate of participation. Finally, more research is needed on birding groups outside of North America.

\section{References}

Applegate, J. E., Otto, R. A., \& Buttitta, J. A. (1982). A cluster analysis of appreciate wildlife users. Wildlife Society Bulletin, 10, 65-70.

Beck, L., \& Cable, T. (1998). Interpretation for the 21st Century: Fifteen guiding principles for interpreting nature and culture. Champaign, IL: Sagamore Publishing.

Boxall, P. C., Stelfox, H. A., \& Hvenegaard, G. T. (1991). A socioeconomic study of urban participants in the 1988 christmas bird count in Alberta. Socioeconomic Technical Report No. 5. Edmonton, AB: Alberta Forestry, Lands and Wildlife.

Boxall, P. C., \& McFarlane, B. L. (1993). Human dimensions of Christmas Bird Counts: Implications for nonconsumptive wildlife recreation programs. Wildlife Society Bulletin, 21, 390-396.

Bramwell, B., \& Fearn, A. (1996). Visitor attitudes to a policy instrument for visitor funding of conservation in a tourist area. Journal of Travel Research, 35(2), 29-33.

Bryan, H. (1977). Leisure value systems and recreational specialization: The case of trout fishermen. Journal of Leisure Research, 9(3), 174-187.

Bryan, H. (2000). Recreation specialization revisited. Journal of Leisure Research, 32(1), $18-21$.

Butler, J. R., \& Fenton, G. D. (1987). Bird watchers of Point Pelee National Park, Canada: Their characteristics and activities with special consideration to their social and resource impacts. Alberta Naturalist, 17(3), 135-146.

Chipman, B. D., \& Helfrich, L. A. (1988). Recreational specialization and motivations of Virginia River anglers. North American Journal of Fisheries Management, 8, 390398.

Cole, J.S., \& Scott, D. (1999). Segmenting participation in wildlife watching: A comparison of casual wildlife watchers and serious birders. Human Dimensions of Wildlife, $4(4), 44-61$.

Ditton, R. B., Loomis, D. K., \& Choi, S. (1992). Recreation specialization: Re-conceptualization from a social worlds perspective. Journal of Leisure Research, 24(1), 33-51. 
Duffus, D. A., \& Dearden, P. (1990). Non-consumptive wildlife-oriented recreation: A conceptual framework. Biological Conservation, 53, 213-231.

Federal-Provincial-Territorial Task Force (1999). The importance of nature to Canadians: Survey highlights. Ottawa, ON: Environment Canada.

Hvenegaard, G. T. (1994). Ecotourism: A status report and conceptual framework. The Journal of Tourism Studies, 5(2), 24-35.

Hvenegaard, G. T., Butler, J. R., \& Krystofiak, D. K. (1989). The economic values of bird watching at Point Pelee National Park, Ontario. Wildlife Society Bulletin, 17, 526531 .

Hvenegaard, G. T., \& Dearden, P. (1998). Ecotourism versus tourism in a Thai national park. Annals of Tourism Research, 25(3), 700-720.

Hvenegaard, G. T., \& Manaloor, V. (2001). The Economic Benefits of the Beaverhill Lake Snow Goose Festival on Tofield, Alberta. Camrose, AB: Augustana University College.

Jacquemot, A., \& Filion, F. L. (1987). The economic significance of birds in Canada. In A.W. Diamond, \& F. L. Filion (Eds.), The value of birds (pp. 15-21). ICBP Technical Publication No. 6. Cambridge, England: International Council for Bird Preservation.

Kellert, S. R. (1985). Birdwatching in American Society. Leisure Sciences, 7, 343-360.

Kerstetter, D. L., Confer, J. J., \& Graefe, A. R. (2001). An exploration of the specialization concept within the context of heritage tourism. Journal of Travel Research 39, 267-274.

Kim, S., Scott, D., \& Crompton, J. L. (1997). An exploration of the relationships among social psychological involvement, behavioral involvement, commitment, and future intentions in the context of birdwatching. Journal of Leisure Research, 29(3), 320341.

Kuentzel, W. F., \& Heberlein, T. A. (1992). Does specialization affect behavioral choices and quality judgments among hunters? Leisure Sciences, 14, 211-226.

Kuentzel, W. F., \& McDonald, C. D. (1992). Differential effects of past experience, commitment, and lifestyle dimensions on river use specialization. Journal of Leisure Research, 24, 269-287.

Manning, R. E. (1986). Studies in Outdoor Recreation. Corvallis, OR: Oregon State University Press.

Martin, S. R. (1997). Specialization and differences in setting preferences among wildlife viewers. Human Dimensions of Wildlife, 2(1), 1-18.

McFarlane, B. L. (1994). Specialization and motivations of birdwatchers. Wildlife Society Bulletin, 22, 361-370.

McFarlane, B. L., \& Boxall, P. C. (1996). Participation in wildlife conservation by birdwatchers. Human Dimensions of Wildlife, 1(3), 1-14.

Norusis, M. J. (1993). SPSS for Windows Professional Statistics Release 6.0. Chicago, IL: SPSS Inc.

Round, P. D. (1989). Birds of Doi Inthanon National Park: Check-list and guide to bird finding. Bangkok, Thailand: Conservation Data Center.

Round, P. D. (1991). Northern Thailand. In H.-U. Bernard and M. Brooke (Eds.), Southeast Asia Wildlife (pp. 115-121). Singapore: APA Publications (HK) Ltd.

Schreyer, R., Lime, D. W., \& Williams, D. R. (1984). Characterizing the influence of past experience on recreation behavior. Journal of Leisure Research 16(1), 34-50. 
Tourism Authority of Thailand (1995). Policies and guidelines: Development of ecotourism (1995-1996) of the tourism authority of Thailand. Bangkok, Thailand: Tourism Authority of Thailand.

Virden, R. J., \& Schreyer, R. (1988). Recreation specialization as an indicator of environmental preference. Environment and Behavior, 20(6), 721-739.

Wellman, J. D., Roggenbuck, J. W., \& Smith, A. C. (1982). Recreation specialization and norms of depreciative behavior among canoeists. Journal of Leisure Research, 14, 323-340.

Witter, D. J., \& Shaw, W. W. (1979). Beliefs of birders, hunters, and wildlife professionals about wildlife management. North American Conference on Wildlife and Natural Resources, 44, 298-305. 
Copyright of Human Dimensions of Wildlife is the property of Taylor \& Francis Ltd and its content may not be copied or emailed to multiple sites or posted to a listserv without the copyright holder's express written permission. However, users may print, download, or email articles for individual use. 